\title{
Promoter Methylation Status of Breast Cancer Susceptibility Gene 1 and 17 Beta Hydroxysteroid Dehydrogenase Type 1 Gene in Sporadic Breast Cancer Patients
}

\author{
Marwa M. Hosny, ${ }^{1}$ Nagwan A. Sabek, ${ }^{1}$ Taghrid B. El-Abaseri, ${ }^{1}$ \\ Fathalla M. Hassan, ${ }^{1}$ and Sherif H. Farrag ${ }^{2}$ \\ ${ }^{1}$ Department of Medical Biochemistry and Molecular Biology, Faculty of Medicine, Suez Canal University, \\ Round Road, Ismailia 41111, Egypt \\ ${ }^{2}$ Surgery Department, Faculty of Medicine, Suez Canal University, Ismailia, Egypt \\ Correspondence should be addressed to Nagwan A. Sabek; nagwan_yasser@yahoo.com
}

Received 11 December 2015; Revised 6 February 2016; Accepted 29 February 2016

Academic Editor: Claudio Luparello

Copyright ( 2016 Marwa M. Hosny et al. This is an open access article distributed under the Creative Commons Attribution License, which permits unrestricted use, distribution, and reproduction in any medium, provided the original work is properly cited.

\begin{abstract}
Epigenetic modifications are involved in breast carcinogenesis. Identifying genes that are epigenetically silenced via methylation could select target patients for diagnostic as well as therapeutic potential. We assessed promoter methylation of breast cancer susceptibility gene 1 (BRCA1) and 17 Beta Hydroxysteroid Dehydrogenase Type 1 (17ßHSD-1) in normal and cancer breast tissues of forty sporadic breast cancer (BC) cases using restriction enzyme based methylation-specific PCR (REMS-PCR). In cancerous tissues, $B R C A 1$ and $17 \beta H S D-1$ were methylated in $42.5 \%$ and $97.5 \%$, respectively, while normal tissues had $35 \%$ and $95 \%$ methylation, respectively. BRCA1 methylation in normal tissues was 12.2 -fold more likely to associate with methylation in cancer tissues $(p<0.001)$. It correlated significantly with increased age at menopause, mitosis, the negative status of Her2, and the molecular subtype "luminal A" ( $p=0.048, p=0.042, p=0.007$, and $p=0.049$, resp.). Methylation of BRCA1 and $17 \beta H S D-1$ related to luminal A subtype of breast cancer. Since a small proportion of normal breast epithelial cells had BRCA1 methylation, our preliminary findings suggest that methylation of BRCA1 may be involved in breast tumors initiation and progression; therefore, it could be used as a biomarker for the early detection of sporadic breast cancer. Methylation of $17 \beta H S D-1$ in normal and cancer tissue could save patients the long term use of adjuvant antiestrogen therapies.
\end{abstract}

\section{Introduction}

Breast cancer is a malignancy arising from the epithelial tissues that line the terminal ductal-lobular units of the breast [1, 2]. Breast cancer $(\mathrm{BC})$ is the most common cancer in females worldwide [3]; BC is the leading cause of cancer death among females, with an estimated 1.7 million cases and 521,900 deaths in 2012; BC alone accounts for $25 \%$ of all cancer cases and $15 \%$ of all cancer deaths among females [4]. Based on data from the National Cancer Registry Program of Egypt (NCRP) in 2008-2011, BC is the most common malignancy among Egyptian females. It constituted $32.0 \%$ of all cancer cases [5]. According to GLOBOCAN 2012, the age-standardized incidence rate (ASR) of breast cancer was 42.3 per 100,000
Egyptian females, with a mortality rate of 17.4 per 100,000 females [4].

Many environmental factors combined with multiple genetic and epigenetic changes are involved in the onset and development of breast cancer [6,7]. The carcinogenesis process is a multistep process during which genetic and epigenetic alterations accumulate in a cell, resulting in the progressive transformation of normal cells through steps of initiation, promotion, and progression into cancer cells [8]. Epigenetics are emerging as one of the most important events in carcinogenesis [9]. DNA methylation has an essential role in the regulation of gene expression in mammalian cells [10]. In normal cells, the majority of promoter cytosine phosphate guanosine $(\mathrm{CpG})$ islands are protected from this epigenetic 
event; thus, they are unmethylated. Conversely, in cancer cells, several promoter $\mathrm{CpG}$ islands are hypermethylated and form a closed repressive chromatin configuration that affects the transcription initiation of the corresponding genes [1113]. Moreover, promoter methylation is a common epigenetic mechanism to silence genes during breast cancer development [14].

Currently, genes that are epigenetically regulated via promoter methylation in breast cancer include cyclin-dependent kinase inhibitor (p16), breast cancer susceptibility gene 1 $(B R C A 1)$, estrogen receptor $(E R \alpha)$, progesterone receptor $(P R)$, retinoic acid receptor- $\beta 2(R A R \beta 2)$, glutathione $\mathrm{S}$ transferase p1 (GSTP1), E-cadherin, and tissue inhibitor of metalloproteinase 3 (TIMP3) [15]. The identification of these methylated promoters had significantly contributed to elucidating the altered molecular pathways in breast carcinoma and provided potential targets for molecular detection [16]. BRCA1 is a tumor suppressor gene that is involved in critical biological processes, including DNA damage repair, cell cycle control, and transcriptional regulation [17]. Silencing of $B R C A 1$ gene via promoter hypermethylation is a common mechanism for its inactivation [18] ranging from 9 to $44 \%$ of sporadic breast cancers [19-21]. Breast cancer, with extensive hypermethylation in the $B R C A 1$ promoter, correlates with a reduced $B R C A 1$ expression [22]. In normal breast tissues, BRCA1 promoter methylation had been identified in $8.3-22 \%$ [23].

The growth of both normal and neoplastic mammary tissue is affected by a number of hormones especially estrogen, which exists in several forms, estrone (E1), estradiol (E2), estriol, estrone sulfate, and estradiol sulfate. E2 is the most biologically active form in the breast tissue. Increasing evidence indicates that intratumoral estrogens derived in situ are mitogenic; thus they promote $\mathrm{BC}$ progression, irrespective of the serum concentrations of ovarian estrogen $[24,25]$.

17 Beta Hydroxysteroid Dehydrogenases (17 $\beta$ HSDs) catalyze the interconversion of active and inactive forms of estrogens within tissues. 17 Beta Hydroxysteroid Dehydrogenase Type $1(17 \beta \mathrm{HSD}-1)$ mainly converts E1 to the potent E2. The encoding gene (17 $\beta$ HSD-1) is located at $17 \mathrm{q} 12-21$, a region that often is rearranged in breast cancer [26]. In a study carried out by Gunnarsson et al., they found amplification of the encoding gene (17 $\beta \mathrm{HSD}-1)$ in $14.5 \%$ of the breast tumors [27]. Meanwhile 17 Beta Hydroxysteroid Dehydrogenase Type 2 $(17 \beta \mathrm{HSD}-2)$ catalyzes the conversion of E2 to E1, thereby reducing estradiol level and hence controlling its proliferative activity [28]. The encoding gene (17 $\beta$ HSD-2) is located at $16 \mathrm{q} 24$ and loss of heterozygosity $(\mathrm{LOH})$ at this site is frequent and early event in breast cancer [29]. Interestingly, BRCA1 had been found to negatively affect estradiol activity by direct interaction with the estrogen receptor, thus controlling the proliferation caused by this steroid hormone [30].

Clinical interest in the treatment of tumors has gained increased impetus interest because the evidence on the use of novel therapeutic agents suggests that DNA promoter methylation is potentially reversible. This may thus allow for the development of future therapeutic interventions [31]. In the light of these evidences and because of the potential roles of estrogens in the early stages of human breast carcinogenesis, in the present study, we aimed to assess the promoter methylation status of both $B R C A 1$ and $17 \beta H S D-1$ genes in the tumor and adjacent normal tissue from sporadic breast cancer patients to establish the role of epigenetic in regulating intratissue estrogen activity and thereby in the etiology of breast cancer.

\section{Material and Methods}

2.1. Tissue Specimen Collection. Surgically resected specimens were freshly obtained at the operation room from forty diagnosed primary breast carcinomas enrolled in the Surgical Oncology Unit in Suez Canal University Hospital during the period from 2013 to 2014. Their matching normal breast tissues, taken $3-5 \mathrm{~cm}$ away from the healthy safety margin of the site of the tumor in the same breast, were obtained to serve as controls. Patients receiving neoadjuvant chemotherapy and/ or hormonal therapy were excluded. Harvested breast tissues were either divided for DNA isolation or kept in 10\% neutralbuffered formalin for histopathological analysis. Labeled tissue sections were examined by a pathologist blinded to the identity of samples and only the researcher would know to whom it referred. Prior to surgical tumor removal, written informed approval consents were obtained from all participants included in the study according to the Ethics Committee of the Faculty of Medicine, Suez Canal University.

2.2. Extraction of Genomic DNA. Genomic DNA was extracted from collected tissues using Qiagen Genomic DNA Purification Kit (cat \# 51304; Qiagen, Hilden, Germany) according to the manufacturer's instructions. The quality of extracted genomic DNA was measured using the NanoDrop(ND-) 1000 Spectrophotometer V3.1.0 (NanoDrop Technologies, Inc., Wilmington, DE, USA).

2.3. Restriction Enzyme Based Methylation-Specific Polymerase Chain Reaction (REMS-PCR). Extracted DNA was digested using the fast restriction enzyme HpaII according to the manufacturer's instructions (Fast Digest ${ }^{\circledR}$, Fermentas, CA, USA). The reaction mixture was incubated at $37^{\circ} \mathrm{C}$ in an oven for 1 hour followed by enzyme inactivation for $10 \mathrm{~min}$ utes at $90^{\circ} \mathrm{C}$. Digested DNA aliquots were then PCR analyzed using BRCA1 and $17 \beta H S D-1$ specific primers [32] encompassing methylation-specific sites (Table 1) and the Taq PCR Master Mix Kit (cat \# 201445; Qiagen, Hilden, Germany). A mock undigested sample containing $1 \mu \mathrm{L}$ of nuclease-free water, instead of $1 \mu \mathrm{L}$ of Fast Digest enzyme (HpaII), was used as a control. A sample of water instead of DNA was used as a negative control for each PCR. PCR was performed for 32 cycles using the following thermal cycling conditions: initial denaturation at $94^{\circ} \mathrm{C}$ for 5 minutes, denaturation at $94^{\circ} \mathrm{C}$ for 30 seconds, primer annealing at $55^{\circ} \mathrm{C}$ or $58^{\circ} \mathrm{C}$ for 30 seconds, extension at $72^{\circ} \mathrm{C}$ for 45 seconds, and a final extension at $72^{\circ} \mathrm{C}$ for 7 minutes. An attempt to perform BRCAI PCRs at higher annealing temperatures gave a total absence of bands. PCR products were detected using ethidium bromide-stained $2 \%$ agarose gels and bands were visualized under UV light. The presence of bands with sizes of $500 \mathrm{bp}$ and $238 \mathrm{bp}$ indicated methylation of $B R C A 1$ and $17 \beta H S D-1$ promoters, respectively, 
TABLE 1: Primers used for PCR amplification after HpaII digestion, along with the target band size and annealing temperatures.

\begin{tabular}{llcr}
\hline Gene & \multicolumn{1}{c}{ Primers sequence $\left(5^{\prime}-3^{\prime}\right)$} & Annealing temperature & Amplicon size \\
\hline FRCA1 & $\begin{array}{l}\text { F: TTGGGAGGGGGCTCGGGCAT } \\
\text { R: CAGAGCTGGCAGCGGACGGT }\end{array}$ & $58^{\circ} \mathrm{C}$ & $500 \mathrm{bp}$ \\
\hline $17 \beta H S D-1$ & $\begin{array}{l}\text { F: AGACCATCCTCACCAACAGG } \\
\text { R: CCTGGCCCTGTCATTTTTAG }\end{array}$ & $55^{\circ} \mathrm{C}$ & $238 \mathrm{bp}$ \\
\hline
\end{tabular}

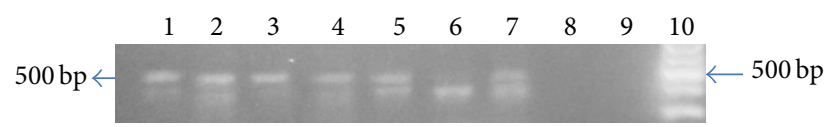

FIGURE 1: A representative gel picture of $2 \%$ agarose gel showing $B R C A 1$ methylation status of two cases. Lanes 1,2,3,4,5, and 7: the presence of $(500 \mathrm{bp})$ band indicates methylation of BRCA1 promoter in these specimens. Lanes 6 and 8 : absence of $(500 \mathrm{bp})$ band indicates the absence of methylation of $B R C A 1$ promoter in these specimens. Lane 9: negative control. Lane 10: 100 bp DNA ladder. Lanes 1 and 5: undigested DNA of normal breast tissue specimens; lanes 2 and 6: digested DNA of normal breast tissue specimens; lanes 3 and 7: undigested DNA of cancerous breast tissue specimens; and lanes 4 and 8: digested DNA of cancerous breast tissue specimens.

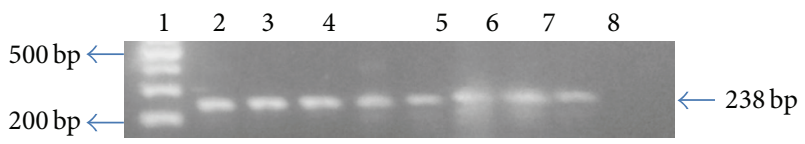

Figure 2: A representative gel picture of ethidium bromide-stained $2 \%$ agarose gel showing $17 \beta H S D-1$ methylation status of two cases. Lane 1: a 100 bp DNA ladder. Lanes $2,3,4,5,6,7,8$, and 9: the presence of (238 bp) band indicates methylation of $17 \beta H S D-1$ promoter in these specimens. Lane 10: negative control. Lanes 2 and 6: undigested DNA of normal breast tissue specimens; lanes 3 and 7: digested DNA of normal breast tissue specimens; lanes 4 and 8: undigested DNA of cancerous breast tissue specimens; and lanes 5 and 9: digested DNA of cancerous breast tissue specimens.

while the absence of these bands indicated a lack of methylation (Figures 1 and 2).

2.4. Statistical Analysis. Coded collected data was analyzed using statistical package SPSS 16.0 for windows (SPSS, Chicago, IL, USA). Student's $t$-test was performed for statistical evaluation of quantitative variable between two independent groups in parametric data with $p<0.05$ considered significant. Chi-square test, described in the form of frequency and percentages, was used to compare a qualitative variable between two independent groups.

\section{Results}

3.1. Association of BRCA1 and $17 \beta H S D-1$ Promoter Methylation with Clinicopathological Parameters. REMS-PCR showed PCR products of the expected sizes $500 \mathrm{bp}$ and $238 \mathrm{bp}$ for BRCA1 and $17 \beta H S D-1$ genes, respectively, in methylated samples, while the absence of these bands indicated a lack of methylation (Figures 1 and 2).

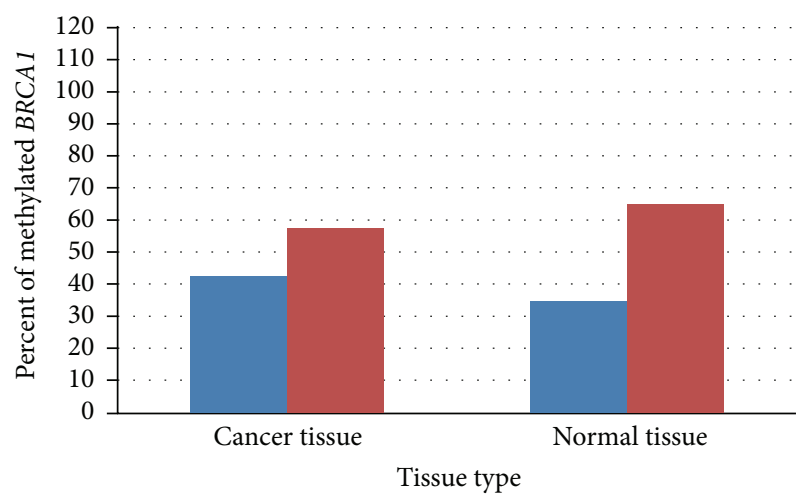

Methylated

Unmethylated

FIGURE 3: Difference between methylation status of BRCA1 promoter in cancer and normal tissue specimens.

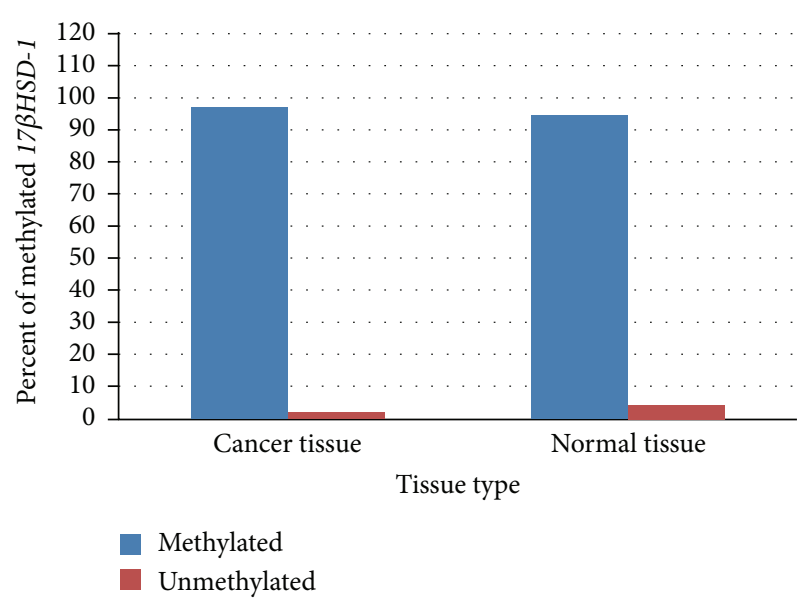

Figure 4: Difference between methylation status of $17 \beta H S D-1$ promoter in cancer and normal tissue specimens.

BRCA1 promoter was methylated in $42.5 \%$ of tumor tissue compared to $35 \%$ in control normal tissue (Figure 3 ). To our surprise, $17 \beta H S D-1$ promoter methylation was seen in $97.5 \%$ of tumor tissues as compared to $95 \%$ of neighboring normal tissue (Figure 4). We found a trend towards BRCA1 and $17 \beta H S D-1$ promoter hypermethylation in cancer tissue specimens of sporadic breast cancer patients compared with controls, although the difference was nonsignificant $(p>$ $0.05)$. 
We categorized our patients into two age groups below 50 years and above or equal to 50 years; there was a nonsignificant increase in $B R C A 1$ promoter methylation of breast cancer tissue specimens in older women compared with younger patients (70.6\% versus $29.4 \%$, resp.) (Table 2 ). Similarly, $17 \beta H S D-1$ promoter methylation, in both study groups, was not associated with age (Table 3), indicating no dramatic effect of age on BRCA1 and $17 \beta H S D-1$ methylation status. Moreover, postmenopausal status was associated with a nonsignificant increased methylation of $B R C A 1$ promoter in cancer tissue specimens compared with premenopausal females (70.6\% versus $29.4 \%$ ), respectively (Table 2 ). In contrast, the mean age at menopause was significantly higher among $B R C A 1$-methylated than the BRCA1-unmethylated group in cancer tissue specimens, as shown in Table 2 (50.7 $\pm 3.1,48.3 \pm$ 3.4 , resp.; $p=0.048$ ). Finally, our results showed no statistically significant difference in $B R C A 1$ promoter methylation in both study groups with tumor size, the number of positive nodes, or tumor stage (Table 2). However, BRCA1-methylated promoter in cancer tissues tended to be of a higher grade (82.4\% methylated versus $69.6 \%$ unmethylated in grade 2 "tumors").

When studying $17 \beta H S D-1$, promoter methylation did not associate with any clinicopathological characteristics in both study groups (Table 3). In addition, $17 \beta H S D-1$ promoter methylation did not correlate with lymph node status, clinical stage, or histological grade (Table 3 ).

\subsection{Association of BRCA1 and 17ßHSD-1 Promoter Methyla-} tion with Molecular Subtypes of Breast Cancer. Methylated $B R C A 1$ in breast cancer specimens correlated with increased mitotic index, the negativity of Her2 receptors, and hence molecular subtype "luminal A" $(p=0.042, p=0.007$, and $p=0.049$, resp.) (Table 4). Although methylation of this promoter tended to be higher in positive estrogen receptor specimens, this correlation was not significant (Table 4). 17ßHSD-1 promoter methylation occurred with almost equal percentages when correlated with all molecular subtypes (Table 5). We observed a high trend towards $17 \beta H S D-1$ promoter methylation in the breast cancer tissue specimens in women who had positive estrogen, progesterone receptors, and negative Her2 (Table 5).

\subsection{The Concordant BRCA1 and $17 \beta H S D-1$ Promoter Methyla-} tion in Cancer and Normal Tissue Specimens. In addition, the concordant promoter methylation of the two studied genes was also investigated (Tables 6 and 7). BRCA1 promoter was methylated in both normal and cancer breast tissue specimens of 11 patients which was statistically significant $(p<$ 0.001 ), while 20 cases showed combined unmethylation of $B R C A 1$ promoter (Table 6).

In the case of a $17 \beta H S D-1$ promoter, 37 tissue specimens had methylated normal and cancer tissues, while none of the studied tissues showed combined unmethylation of this gene promoter (Table 7).

3.4. Combined BRCA1 and 17ßHSD-1 Promoter Methylation in Both Study Groups. Among the studied samples, $45 \%$ of cancer tissues and $35 \%$ of normal tissues had combined BRCA1 and $17 \beta H S D-1$ promoter methylation (Table 8). However, there was no significant relation between combined BRCA1 and $17 \beta H S D-1$ promoter methylation and type of tissue. The odds ratio $=1.5 ; 95 \%$ confidence interval $=0.6-3.7$ and $p=$ 0.361 .

\section{Discussion}

$B R C A 1$ promoter hypermethylation is implicated as one of the mechanisms of loss of gene expression [33]. It was identified in $9-44 \%$ of sporadic breast cancers [19-21]. The mitogenic effect of estradiol on breast epithelium is counteracted by the upregulation of $B R C A 1$ expression, which in turn exerts a negative feedback effect on estradiol action by direct interaction with estrogen receptor [30]. Hence, transcriptional inactivation of $B R C A 1$ due to methylation may fail to decrease estradiol activity resulting in increased breast tissue proliferation. Despite the ample studies on the role of BRCA1 in BC and its epigenetic modification, nevertheless, its association with the estrogen level regulating gene $17 \beta H S D-1$ has not been conducted. In this study, we investigated the methylation status of BRCA1 and $17 \beta H S D-1$ in sporadic breast cancer Egyptian patients and correlated the findings to those in normal breast tissues.

BRCA1 methylation percentage in our study is near to the upper end of previously reported frequencies for this alteration in sporadic breast cancer [19-21]. Hsu et al. data had hypermethylation of the BRCA1 in 56\% (78 of 139) of Taiwanese women with early-stage sporadic breast carcinomas, which is significantly higher than previously reported frequencies for this alteration in sporadic breast tumors [34]. The incidence of BRCA1 methylation has previously been reported to be higher in breast tumors of infiltrating ductal type suggesting that it might play a role in breast carcinogenesis [19]. In other studies, BRCA1 existed in even lower percentages, $9-32 \%$, in sporadic breast cancer [33]. This variation may be due to several factors: first factor is the methylation assay or the analysis method used [35], bisulfite method $[15,19,36,37]$, and genomic sequencing $[22,38,39]$; secondly, MSP detects differential methylation status by amplification of bisulfite-treated DNA with primers specific for methylated versus unmethylated DNA [40]. CpG sites residing within the primer sets were used as a proxy for the methylation status of the region of interest. Although most published studies mentioned above $[15,19,36,37]$ used MSP, the primer sequences and target regions varied from study to study. Finally, contaminating unmethylated normal tissue may occur during tissue dissection that might attenuate the methylation levels of the tumor tissue.

A small population of apparently normal breast epithelial cells could harbor BRCA1 promoter methylation in patients' samples with BRCA1-methylated tumors [41, 42], but not in those with BRCA1-unmethylated tumors. BRCA1 promoter was methylated in both normal and cancer breast tissue specimens of 11 patients which was statistically significant $(p<0.001)$, while 20 cases showed combined unmethylation of BRCA1 promoter. In the case of $17 \beta H S D-1$ promoter, 37 tissue specimens had methylated normal and cancer tissues, 


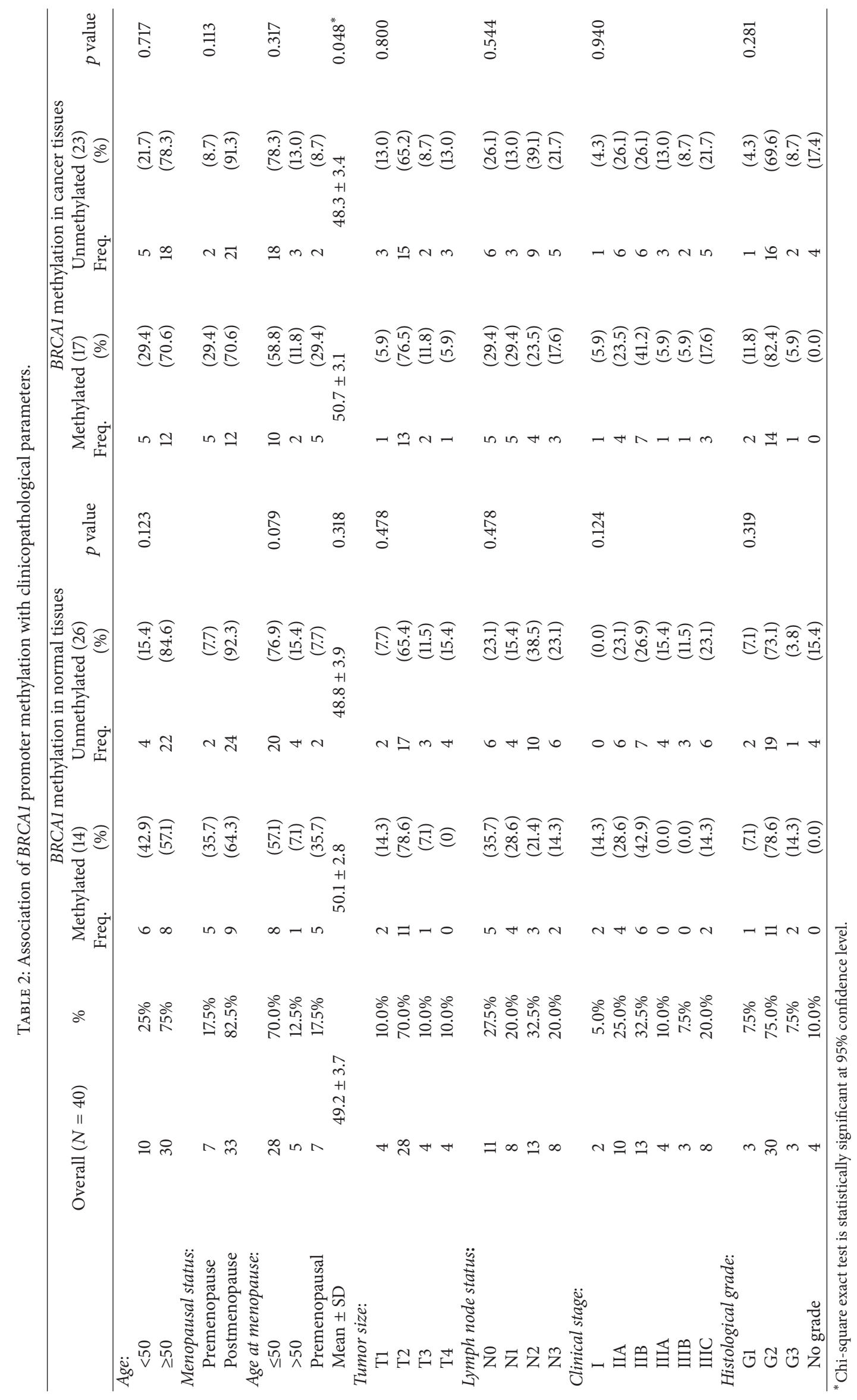




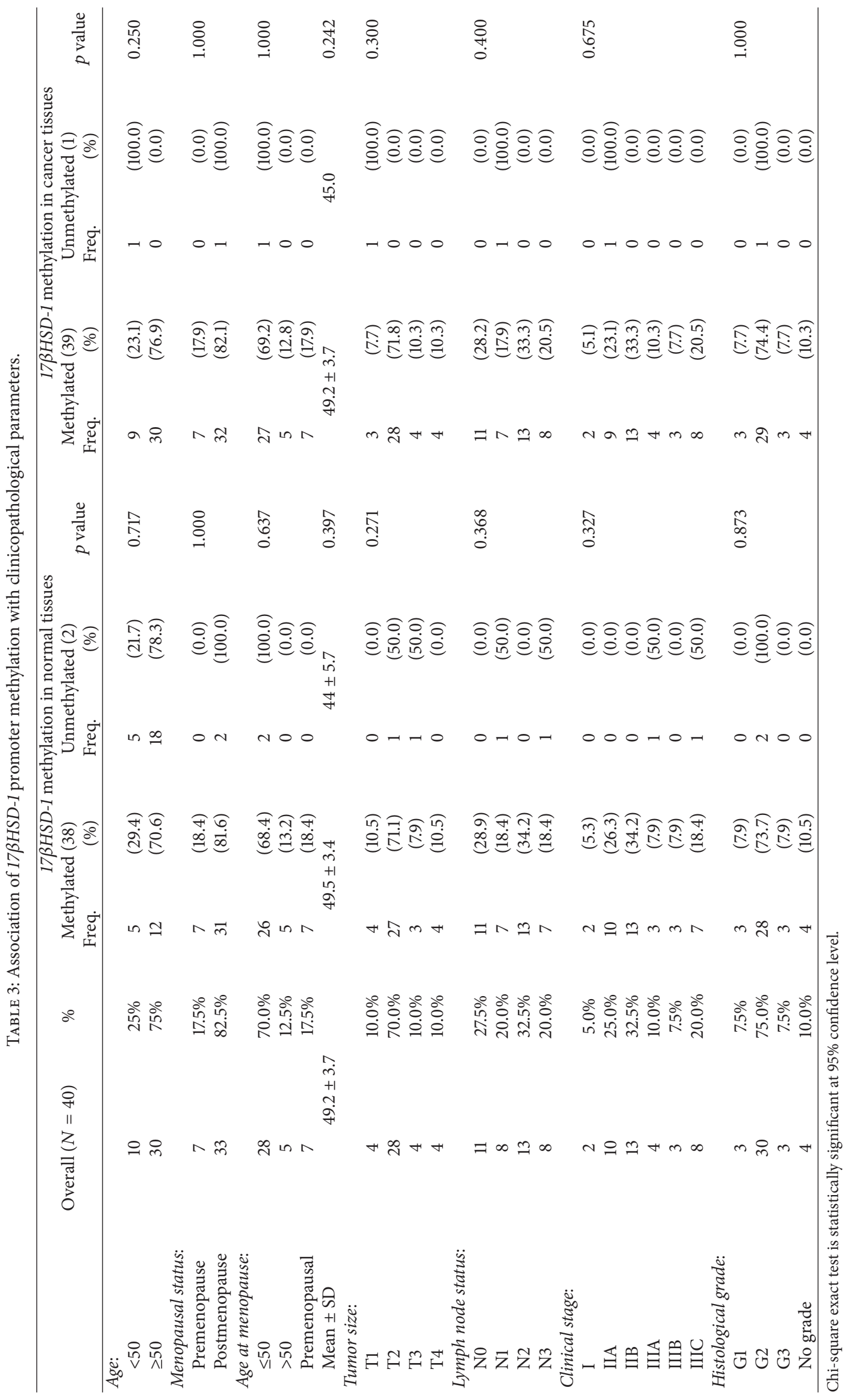




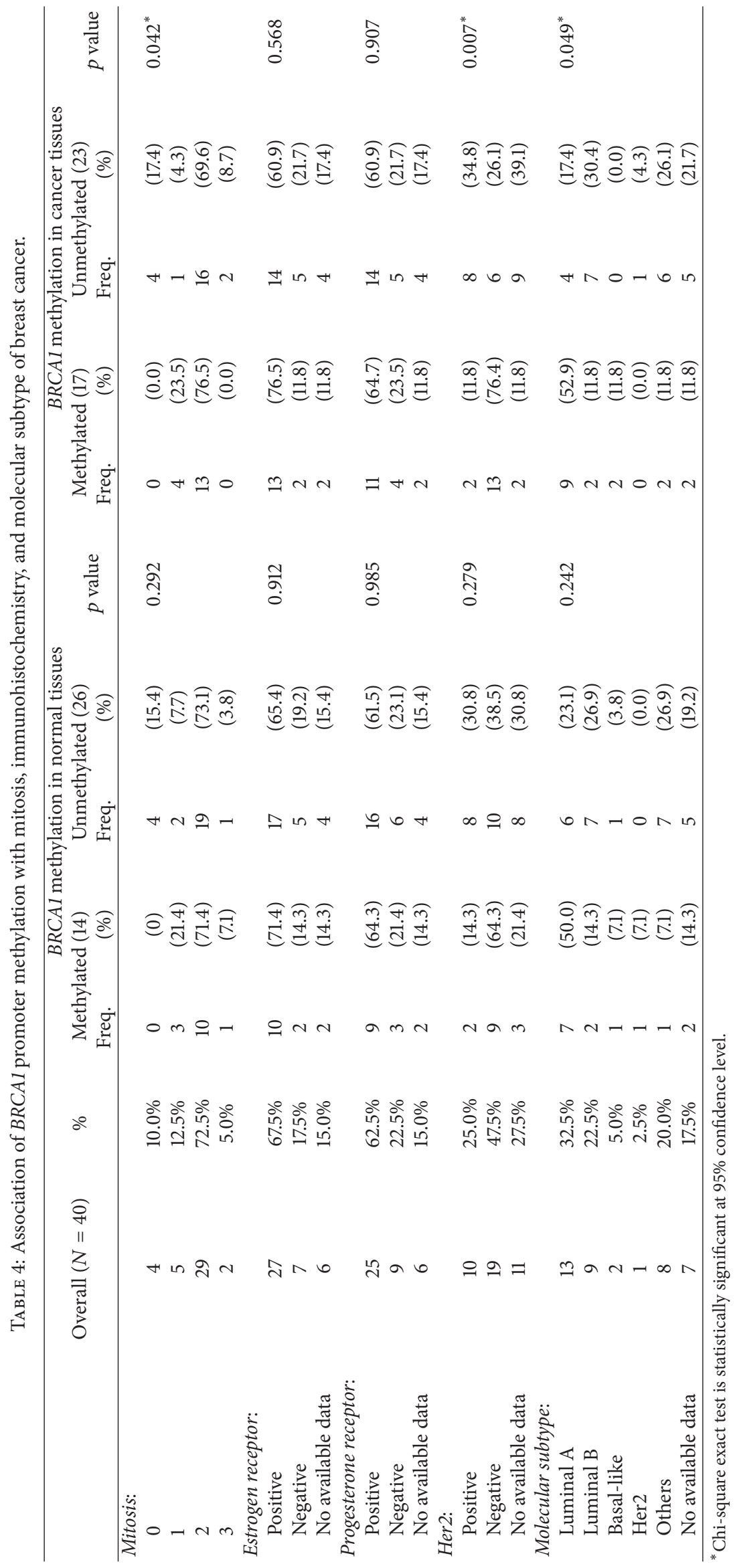




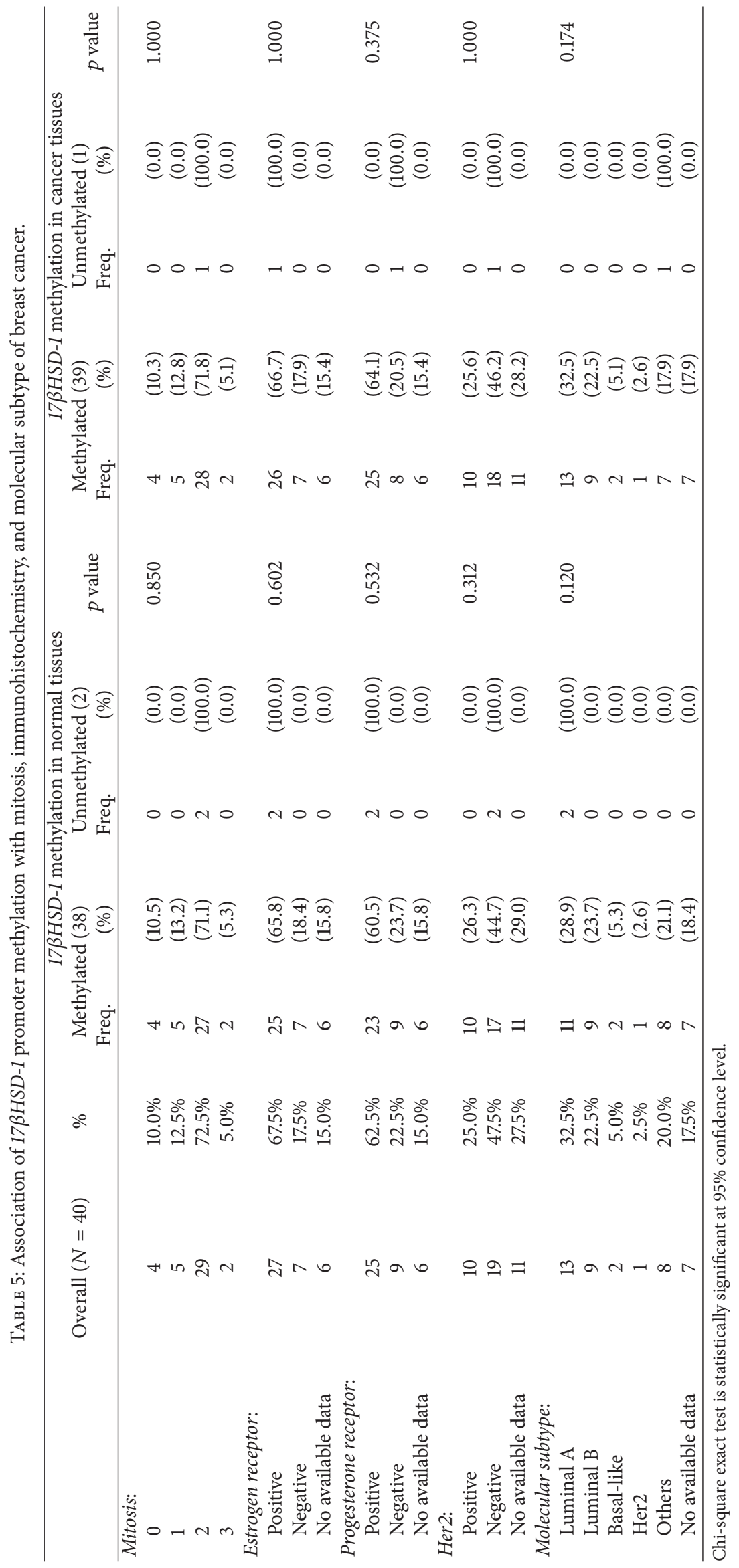


TABLE 6: Relation between methylation status of BRCA1 promoter in cancer tissue specimens and normal tissue specimens in 40 sporadic breast cancer patients.

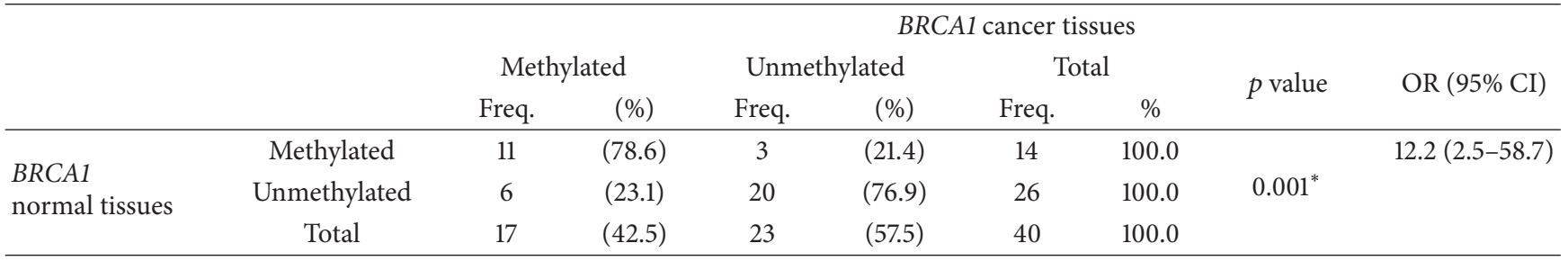

${ }^{*}$ Chi-square test is statistically significant at $95 \%$ confidence level.

TABLE 7: Relation between methylation status of $17 \beta H S D-1$ promoter in cancer tissue specimens and normal tissue specimens in 40 sporadic breast cancer patients.

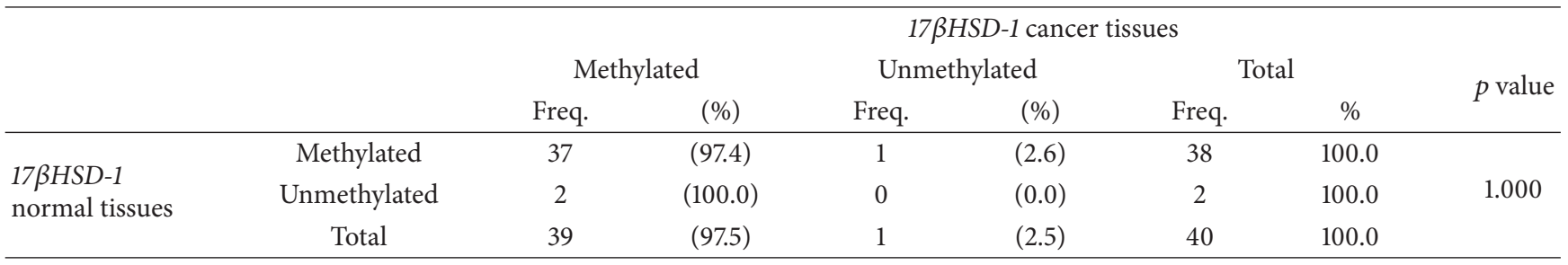

Chi-square test is statistically significant at $95 \%$ confidence level.

while none of the studied tissues showed combined unmethylation of this gene promoter.

BRCA1 methylation was detected in $76.5 \%$ of cancer tissues with positive ER and $64.7 \%$ with positive PR; on the other hand, methylation was significantly $(p=0.007)$ higher among tissues with negative Her2 (68.4\%) than those with positive Her2, while $17 \beta H S D-1$ promoter methylation was found in cancer tissue specimens in women who had positive ER (66.7\%), positive PR (64.1\%), and negative Her2 (46.2\%).

Although we could not have complete data for the ER, $\mathrm{PR}$, and Her2 receptor staining status for the entire studied sample size, our data showed that "luminal A" molecular subtype, defined as being positive for both ER and PR but negative for Her2 receptor, had the highest level of promoter methylation. In particular, $17 \beta H S D-1$ showed the highest association with "luminal A" subtype. Similarly, methylation of BRCA1 promoter correlated significantly with "luminal A" subtype and was evenly distributed among other molecular subtypes. Our finding that $17 \beta H S D-1$ is associated with the luminal subtypes A and B is surprising since it has been shown that this enzyme activity correlates with the positivity of both ER and PR [28]. Methylation of 17ßHSD-1 in both normal and cancer tissue specimens directs the attentions towards saving those patients from the long term use of adjuvant antiestrogen therapies. Although our results indicated that BRCA1 promoter methylation did not correlate significantly with triple-negative breast cancer $(p=0.174)$, Bal et al. showed that $B R C A 1$ promoter methylation correlated with decreased expression of ER and basal-like phenotype [33]. More than half of the patients with the BRCA1 mutation had triple-negative breast cancer, and they also shared common clinical and pathological features [43]. However, a significant portion of triple-negative breast cancer patients does not carry BRCA1 mutations. In studies of US and British women, triple-negative/basal-like tumors appeared to be more common among black women (especially before menopause) compared to white women $[44,45]$.

Theoretically, unmethylated/hypomethylated $17 \beta H S D-1$ should increase the levels of active estradiol and the risk of BC. Contrary to this, we observed that methylation of $17 \beta H S D-1$ was seen in $97.5 \%$ of tumor tissue compared to $95 \%$ of neighboring normal tissue. Some genes are known to alter their methylation status with age and these are usually tissue-specific [33]. Our results showed that the mean age of sporadic breast cancer patients with $17 \beta H S D-1$ promoters methylation group $(56.0 \pm 9.3$ years $)$ was slightly higher than unmethylated group (49.0 years), although the relation between age and $17 \beta H S D-1$ methylation was statistically insignificant. The present study, therefore, indicates that the methylation status of $17 \beta H S D-1$ may be age-specific; alteration of this methylation pattern of the $17 \beta H S D-1$ gene in breast tissue may play an important role in BC progression.

Our preliminary results presented here only demonstrate the association of $B R C A 1$ promoter methylation between tumors and normal breast tissues. Direct evidence shows that progression from $B R C A 1$-methylated normal breast epithelial cells to BRCA1-methylated breast cancer needs to be investigated in future studies. The high methylation of $17 \beta H S D-1$ promoter in both normal and cancer breast tissues rules out the biological significance of this epigenetic modification in distinguishing normal and cancer tissues. Given the fact that breast tumors express high heterogeneity, one limitation in explaining this finding is the small sample size of our studied population. Suzuki et al. showed that $17 \beta$ HSD-1 negative breast tissues are less differentiated; hence, they escape normal regulation of proliferation; thus, it is possible that the reduced expression of this enzyme via hypermethylation in normal tissue reflects an increased carcinogenic potential 
TABLE 8: Relation between combined BRCA1 and 17 $\beta H S D-1$ promoter methylation and the type of breast tissues of 40 sporadic breast cancer patients.

\begin{tabular}{lcccccccc}
\hline & \multicolumn{7}{c}{ Combined $B R C A 1$ and $17 \beta H S D-1$ promoter methylation } \\
& \multicolumn{2}{c}{ Overall $(N=40)$} & \multicolumn{2}{c}{ Methylated } & \multicolumn{2}{c}{ Unmethylated } & P value & OR (95\% CI) \\
& Freq. & $\%$ & Freq. & $(\%)$ & Freq. & $(\%)$ & \\
Type of tissue & & & & & & & \\
Cancer tissues & 40 & $100.0 \%$ & 18 & $(45.0)$ & 22 & $(55.0)$ & 0.361 & $1.5(0.6-3.7)$ \\
Normal tissues & 40 & $100.0 \%$ & 14 & $(35.0)$ & 26 & $(65.0)$ & \\
Total & 80 & $100.0 \%$ & 32 & $(40.0)$ & 48 & $(60.0)$ & \\
\hline
\end{tabular}

Chi-square test is statistically significant at $95 \%$ confidence level.

in normal breast tissues harboring a nearby cancer tumor [28]. In addition, based on the fact that the activity of both $17 \beta H S D-2$ and $17 \beta H S D-1$ controls the in situ level of breast estrogen, it is possible that $17 \beta H S D-2$ activity is dominating the control of estrogen level in the $17 \beta H S D-1$ hypermethylated tumors and it would be beneficial to evaluate the methylation status of this gene especially in breast cancer hypermethylated $17 \beta H S D-1$ tissues [46]. Furthermore, we found that methylation of $17 \beta H S D-1$ in both normal and cancer tissue specimens may direct the attentions towards saving those patients from the long term use of adjuvant antiestrogen therapies, for example, tamoxifen, especially in $\mathrm{ER}^{+}$. Increased understanding of the genetic/epigenetic abnormality in the pathogenesis of breast cancer is crucial and may provide a basis for detection and treatment. This study highlights the frequent promoter methylation of $B R C A 1$ and its prognostic significance, irrespective of $B R C A 1$ gene mutation in Egyptian patients with early-stage breast cancer.

In conclusion, we showed that a significant proportion of patients with BRCA1-methylated tumors harbored BRCA1 promoter methylation in normal breast tissues and that $17 \beta H S D-1$ methylation was observed in the normal tissues of the $17 \beta H S D-1$ promoter methylation status of the tumors. This suggests a possibility that a small proportion of the epithelial cells with $B R C A 1$ promoter methylation can be precursor cells from which BRCA1-methylated breast tumors originate. Although our preliminary results presented here need to be validated by future studies, they may provide further insight into the different roles of promoter methylation of these genes in breast carcinogenesis.

\section{Competing Interests}

The authors declare that they have no competing interests.

\section{Acknowledgments}

The authors are indebted to the participants for their utmost cooperation.

\section{References}

[1] J. R. C. Sainsbury, T. J. Anderson, and D. A. L. Morgan, "ABC of breast diseases: breast cancer," British Medical Journal, vol. 321, no. 7263, pp. 745-750, 2000.
[2] T. Gudjonsson, M. C. Adriance, M. D. Sternlicht, O. W. Petersen, and M. J. Bissell, "Myoepithelial cells: their origin and function in breast morphogenesis and neoplasia," Journal of Mammary Gland Biology and Neoplasia, vol. 10, no. 3, pp. 261-272, 2005.

[3] C. E. DeSantis, C. C. Lin, A. B. Mariotto et al., "Cancer treatment and survivorship statistics, 2014," CA: A Cancer Journal for Clinicians, vol. 64, no. 4, pp. 252-271, 2014.

[4] L. A. Torre, F. Bray, R. L. Siegel, J. Ferlay, J. Lortet-Tieulent, and A. Jemal, "Global cancer statistics, 2012," CA: Cancer Journal for Clinicians, vol. 65, no. 2, pp. 87-108, 2015.

[5] A. S. Ibrahim, H. M. Khaled, N. N. Mikhail, H. Baraka, and H. Kamel, "Cancer incidence in Egypt: results of the national population-based cancer registry program," Journal of Cancer Epidemiology, vol. 2014, Article ID 437971, 18 pages, 2014.

[6] B. Sadikovic, K. Al-Romaih, J. A. Squire, and M. Zielenska, "Cause and consequences of genetic and epigenetic alterations in human cancer," Current Genomics, vol. 9, no. 6, pp. 394-408, 2008.

[7] R. M. Brena and J. F. Costello, "Genome-epigenome interactions in cancer," Human Molecular Genetics, vol. 16, no. 1, pp. R96-R105, 2007.

[8] M. Esteller, "CpG island hypermethylation and tumor suppressor genes: a booming present, a brighter future," Oncogene, vol. 21, no. 35, pp. 5427-5440, 2002.

[9] S. B. Baylin and J. G. Herman, "DNA hypermethylation in tumorigenesis: epigenetics joins genetics," Trends in Genetics, vol. 16, no. 4, pp. 168-174, 2000.

[10] S. Eden and H. Cedar, "Role of DNA methylation in the regulation of transcription," Current Opinion in Genetics and Development, vol. 4, no. 2, pp. 255-259, 1994.

[11] S. B. Baylin and J. E. Ohm, "Epigenetic gene silencing in cancer-a mechanism for early oncogenic pathway addiction?" Nature Reviews Cancer, vol. 6, no. 2, pp. 107-116, 2006.

[12] M. Widschwendter, S. Apostolidou, E. Raum et al., "Epigenotyping in peripheral blood cell DNA and breast cancer risk: a proof of principle study," PLOS ONE, vol. 3, no. 7, Article ID e2656, 2008.

[13] M. Esteller, P. G. Corn, S. B. Baylin, and J. G. Herman, "A gene hypermethylation profile of human cancer," Cancer Research, vol. 61, no. 8, pp. 3225-3229, 2001.

[14] K. P. Suijkerbuijk, M. J. Fackler, S. Sukumar et al., "Methylation is less abundant in BRCAl-associated compared with sporadic breast cancer," Annals of Oncology, vol. 19, no. 11, pp. 1870-1874, 2008.

[15] A. Catteau and J. R. Morris, "BRCA1 methylation: a significant role in tumour development?" Seminars in Cancer Biology, vol. 12, no. 5, pp. 359-371, 2002. 
[16] S. Karray-Chouayekh, F. Trifa, A. Khabir et al., "Clinical significance of epigenetic inactivation of hMLH1 and BRCA1 in tunisian patients with invasive breast carcinoma," Journal of Biomedicine and Biotechnology, vol. 2009, Article ID 369129, 7 pages, 2009.

[17] N. Andrieu, D. E. Goldgar, D. F. Easton et al., "Pregnancies, breast-feeding, and breast cancer risk in the International BRCA1/2 Carrier Cohort Study (IBCCS)," Journal of the National Cancer Institute, vol. 98, no. 8, pp. 535-544, 2006.

[18] J. C. Rice, K. S. Massey-Brown, and B. W. Futscher, "Aberrant methylation of the BRCA1 CpG island promoter is associated with decreased BRCA1 mRNA in sporadic breast cancer cells," Oncogene, vol. 17, no. 14, pp. 1807-1812, 1998.

[19] V. Birgisdottir, O. A. Stefansson, S. K. Bodvarsdottir, H. Hilmarsdottir, J. G. Jonasson, and J. E. Eyfjord, "Epigenetic silencing and deletion of the BRCA1 gene in sporadic breast cancer," Breast Cancer Research, vol. 8, no. 4, article R38, 2006.

[20] N. Al-Moghrabi, A. J. S. Al-Qasem, and A. Aboussekhra, "Methylation-related mutations in the BRCA1 promoter in peripheral blood cells from cancer-free women," International Journal of Oncology, vol. 39, no. 1, pp. 129-135, 2011.

[21] D. T. Butcher and D. I. Rodenhiser, "Epigenetic inactivation of BRCA1 is associated with aberrant expression of CTCF and DNA methyltransferase (DNMT3B) in some sporadic breast tumours," European Journal of Cancer, vol. 43, no. 1, pp. 210-219, 2007.

[22] A. B. Ali, P. T. C. Iau, and J.-H. Sng, "Cancer-specific methylation in the BRCA1 promoter in sporadic breast tumours," Medical Oncology, vol. 28, no. 1, pp. 64-66, 2011.

[23] R. G. Dumitrescu, C. Marian, S. S. Krishnan et al., "Familial and racial determinants of tumor suppressor genes promoter hypermethylation in breast tissues from healthy women," Journal of Cellular and Molecular Medicine, vol. 14, no. 6, pp. 1468-1475, 2010.

[24] H. Sasano, T. Suzuki, J. Takeyama et al., "17-Beta-hydroxysteroid dehydrogenase in human breast and endometrial carcinoma. A new development in intracrinology," Oncology, vol. 59, no. 1, pp. $5-12,2000$.

[25] H. Sasano, T. Suzuki, T. Nakata, and T. Moriya, "New development in intracrinology of breast carcinoma," Breast Cancer, vol. 13, no. 2, pp. 129-136, 2006.

[26] P. Kauraniemi, M. Bärlund, O. Monni, and A. Kallioniemi, "New amplified and highly expressed genes discovered in the ERBB2 amplicon in breast cancer by cDNA microarrays," Cancer Research, vol. 61, no. 22, pp. 8235-8240, 2001.

[27] C. Gunnarsson, M. Ahnström, K. Kirschner et al., "Amplification of HSD17B1 and ERBB2 in primary breast cancer," Oncogene, vol. 22, no. 1, pp. 34-40, 2003.

[28] T. Suzuki, T. Moriya, N. Ariga, C. Kaneko, M. Kanazawa, and H. Sasano, "17 $\beta$-hydroxysteroid dehydrogenase type 1 and type 2 in human breast carcinoma: a correlation to clinicopathological parameters," British Journal of Cancer, vol. 82, no. 3, pp. 518-523, 2000.

[29] A.-M. Cleton-Jansen, D. F. Callen, R. Seshadri et al., "Loss of heterozygosity mapping at chromosome arm 16q in 712 breast tumors reveals factors that influence delineation of candidate regions," Cancer Research, vol. 61, no. 3, pp. 1171-1177, 2001.

[30] F. Magdinier, L.-M. Billard, G. Wittmann et al., "Regional methylation of the $5^{\prime}$ end $\mathrm{CpG}$ island of BRCA1 is associated with reduced gene expression in human somatic cells," The FASEB Journal, vol. 14, no. 11, pp. 1585-1594, 2000.

[31] M. P. Horan, "Methylation-mediated transcriptional silencing in tumorigenesis," in $e L S$, John Wiley \& Sons, New York, NY, USA, 2011.

[32] V. Bhavani, M. Srinivasulu, Y. R. Ahuja, and Q. Hasan, "Role of BRCA1, HSD17B1 and HSD17B2 methylation in breast cancer tissue," Cancer Biomarkers, vol. 5, no. 4-5, pp. 207-213, 2009.

[33] A. Bal, S. Verma, K. Joshi et al., "BRCA1-methylated sporadic breast cancers are BRCA-like in showing a basal phenotype and absence of ER expression," Virchows Archiv, vol. 461, no. 3, pp. 305-312, 2012.

[34] N. C. Hsu, Y. F. Huang, K. K. Yokoyama, P. Y. Chu, F. M. Chen, and M. F. Hou, "Methylation of BRCAl promoter region is associated with unfavorable prognosis in women with earlystage breast cancer," PLoS ONE, vol. 8, no. 2, p. 6, 2013.

[35] T. Bianco, G. Chenevix-Trench, D. C. A. Walsh, J. E. Cooper, and A. Dobrovic, "Tumour-specific distribution of BRCA1 promoter region methylation supports a pathogenetic role in breast and ovarian cancer," Carcinogenesis, vol. 21, no. 2, pp. 147-151, 2000.

[36] M. Esteller, J. M. Silva, G. Dominguez et al., "Promoter hypermethylation and BRCA1 inactivation in sporadic breast and ovarian tumors," Journal of the National Cancer Institute, vol. 92, no. 7, pp. 564-569, 2000.

[37] S. Mirza, G. Sharma, C. P. Prasad et al., "Promoter hypermethylation of TMS1, BRCA1, ER $\alpha$ and PRB in serum and tumor DNA of invasive ductal breast carcinoma patients," Life Sciences, vol. 81, no. 4, pp. 280-287, 2007.

[38] D. N. Mancini, D. I. Rodenhiser, P. J. Ainsworth et al., "CpG methylation within the 5 ' regulatory region of the BRCA1 gene is tumor specific and includes a putative CREB binding site," Oncogene, vol. 16, no. 9, pp. 1161-1169, 1998.

[39] F. Cai, I. Ge, M. Wang, E. Biskup, X. Lin, and X. Zhong, "Pyrosequencing analysis of BRCA1 methylation level in breast cancer cells," Tumor Biology, vol. 35, no. 4, pp. 3839-3844, 2014.

[40] J. G. Herman, J. R. Graff, S. Myöhänen, B. D. Nelkin, and S. B. Baylin, "Methylation-specific PCR: a novel PCR assay for methylation status of CpG islands," Proceedings of the National Academy of Sciences of the United States of America, vol. 93, no. 18, pp. 9821-9826, 1996.

[41] C. Snell, M. Krypuy, E. M. Wong, M. B. Loughrey, and A. Dobrovic, "BRCA1 promoter methylation in peripheral blood DNA of mutation negative familial breast cancer patients with a BRCA1 tumour phenotype," Breast Cancer Research, vol. 10, no. 1, article R12, 2008.

[42] Y. Otani, T. Miyake, N. Kagara et al., "BRCA1 promoter methylation of normal breast epithelial cells as a possible precursor for BRCA1-methylated breast cancer," Cancer Science, vol. 105, no. 10, pp. 1369-1376, 2014.

[43] G. Rennert, S. Bisland-Naggan, O. Barnett-Griness et al., "Clinical outcomes of breast cancer in carriers of BRCA1 and BRCA2 mutations," New England Journal of Medicine, vol. 357, no. 2, pp. 115-123, 2007.

[44] H. M. Sineshaw, M. Gaudet, E. M. Ward et al., "Association of race/ethnicity, socioeconomic status, and breast cancer subtypes in the National Cancer Data Base (2010-2011)," Breast Cancer Research and Treatment, vol. 145, no. 3, pp. 753-763, 2014. 
[45] N. Howlader, S. F. Altekruse, C. I. Li et al., "US incidence of breast cancer subtypes defined by joint hormone receptor and HER2 status," Journal of the National Cancer Institute, vol. 106, no. 5, Article ID dju055, 2014.

[46] C. Gunnarsson, E. Hellqvist, and O. Stål, "17 $\beta$-hydroxysteroid dehydrogenases involved in local oestrogen synthesis have prognostic significance in breast cancer," British Journal of Cancer, vol. 92, no. 3, pp. 547-552, 2005. 


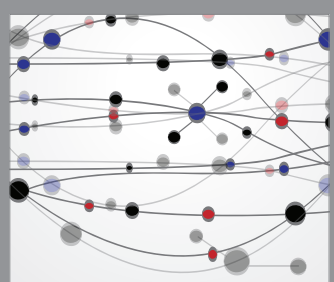

The Scientific World Journal
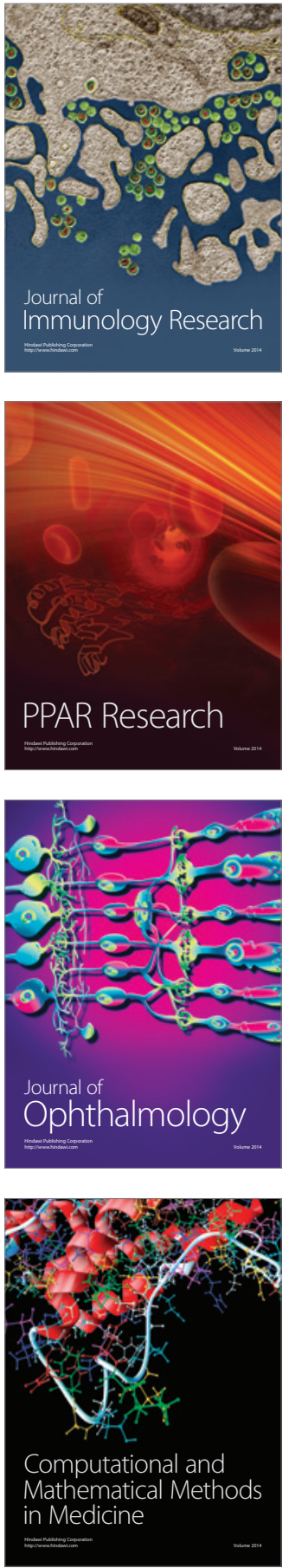

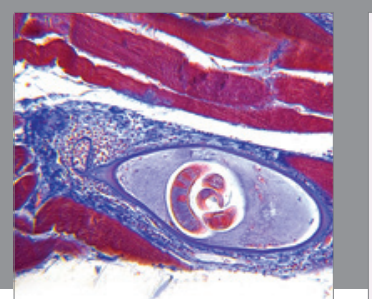

Gastroenterology Research and Practice

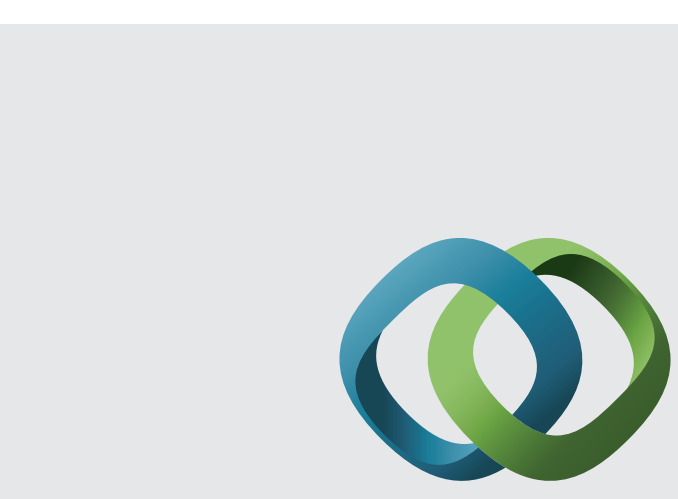

\section{Hindawi}

Submit your manuscripts at

http://www.hindawi.com
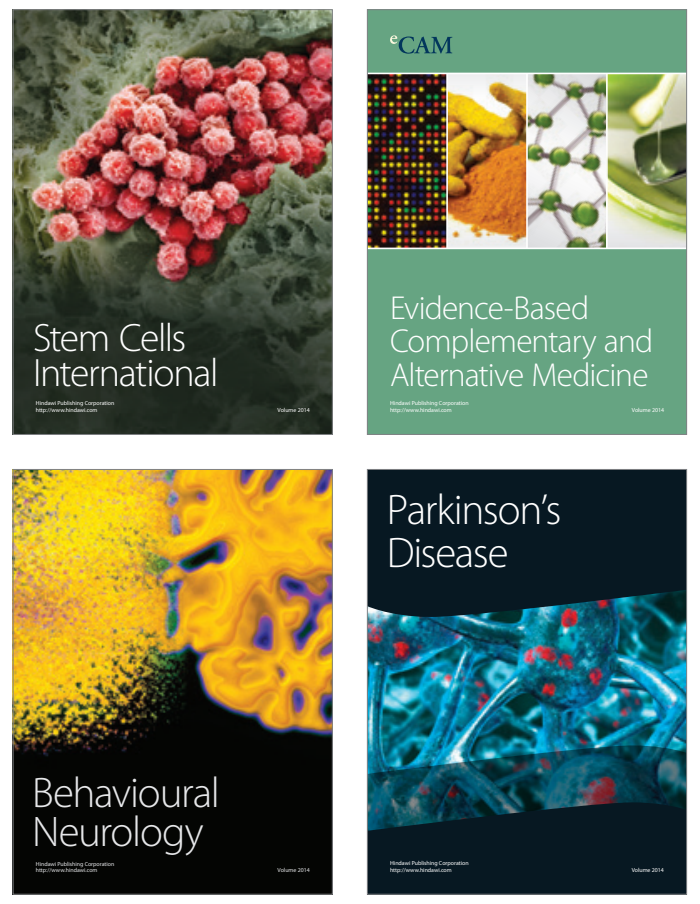
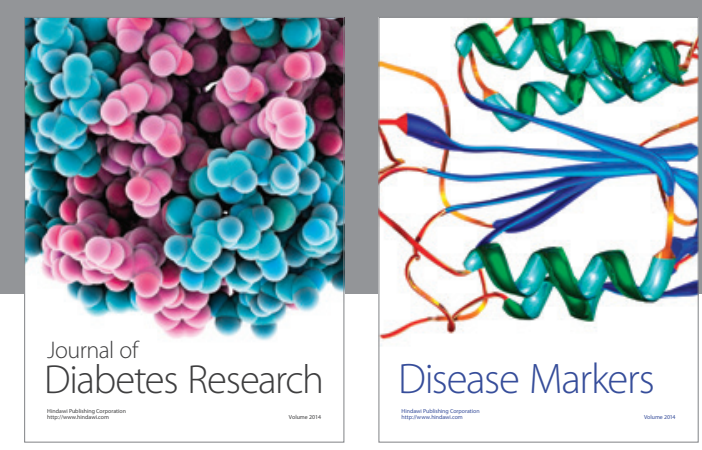

Disease Markers
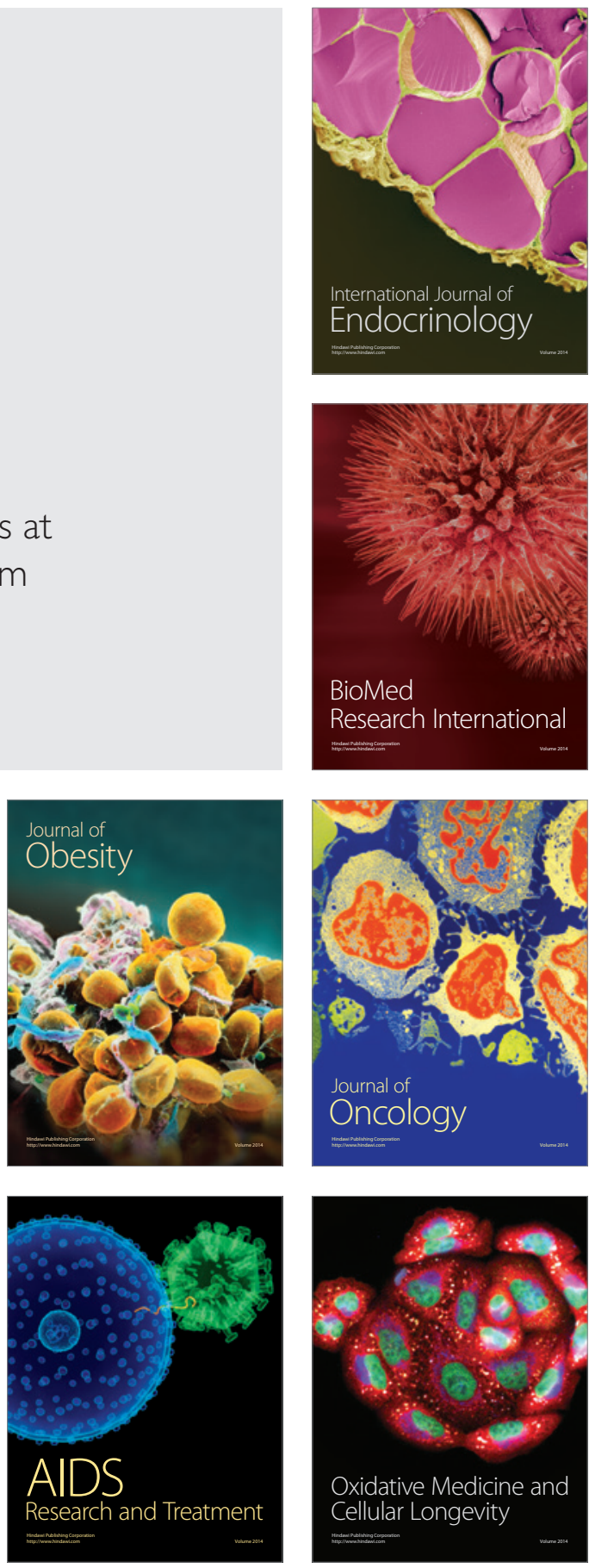